\title{
O Outro e a violência social: possibilidades de compreensões em práticas sociais
}

\author{
The Other and social violence: possibilities of comprehensions in social practices \\ El Otro y la violencia social: posibilidades de comprensiones en prácticas sociales \\ Paulo Henrique Leal ${ }^{1}$; Aida Victoria Garcia Montrone ${ }^{2}$ \\ Instituto Federal de São Paulo, IFSP, Piracicaba-SP, Brasil \\ Universidade Federal de São Carlos, UFSCAR, SÃo CARLOS-SP, BraSIL
}

\begin{abstract}
RESUMO
Com base nos estudos de natureza qualitativa e suleado por referenciais latino-americanos, o objetivo deste estudo foi descrever possibilidades de compreensões com o Outro e de seu reconhecimento em práticas sociais. Para tanto, foi realizada uma incursão à literatura acerca das temáticas referentes à violência social, conceituação de Outro, práticas sociais e processos educativos, bem como a indicação de algumas pesquisas já realizadas, como possibilidades intencionalizadas a um mundo mais justo, dialógico e, portanto, humanizado. Estranhar-se, respeitar, confiar, empatizar, dialogar e caminhar no face a face são ações de amorosidade imperativas ao reconhecimento da humanidade do Outro e, portanto, dos nossos próprios processos de superação da violência social. Assim, torna-se possível a construção de laços e costuras mutuamente solidárias, na abertura ao desvelar(-se) e ao tecer dos processos educativos ao longo da convivência dialógica, investigativa ou não, em práticas sociais.
\end{abstract}

Palavras-chave: Processos Educativos. Violência Social. Convivência Dialógica.

\begin{abstract}
Based on studies of qualitative origin and guided by Latin American references, the objective of this study was to describe possibilities of understanding with the Other and their recognition in social practices. In order to do so, an incursion into the literature on social violence, conceptualization of Other, social practices and educational processes was carried out, as well as the indication of some research already done, as intentional possibilities for a fairer world, dialogical and therefore, humanized. Strangeness, respect, trust, empathy, dialog and walk face to face are acts of love that are imperative to the recognition of the humanity of the Other, and therefore of our own processes of overcoming social violence. That way, it becomes possible to build ties and seams mutually supportive, in the opening when unveiling and weaving of the educational processes along the dialogical coexistence, investigative or not, in social practices.
\end{abstract}

Keywords: Educational Processes. Social Violence. Dialogical Coexistence.

\section{RESUMEN}

Con base en los estudios de origen cualitativo y suleados por referenciales latinoamericanos, el objetivo de este estudio fue describir posibilidades de comprensión con el Otro y de su reconocimiento en prácticas sociales. Para ello, se realizó una incursión a la literatura acerca de las temáticas referentes a la violencia social, conceptualización de Otro, prácticas sociales y procesos educativos, así como la indicación de algunas investigaciones ya realizadas, como posibilidades intencionalizadas a un mundo más justo, dialógico y, por lo tanto, , humanizado. Cuestionar a si, respetar, confiar, tener empatía, dialogar y caminar en la cara a cara son acciones de amorosidad imperativas al reconocimiento de la humanidad del Otro y, por tanto, de nuestros propios procesos de superación de la violencia social. Así, se hace posible la construcción de lazos y costuras mutuamente solidarias, en la apertura al desvelar(se) y el tejer de los procesos educativos a lo largo de la convivencia dialógica, investigativa o no, en prácticas sociales.

Palabras clave: Procesos Educativos. Violencia Social. Convivencia Dialógica.

\footnotetext{
${ }^{1}$ Professor do IFSP Piracicaba. E-mail: paulinho@ifsp.edu.br

2 Professora Associada do Departamento de Metodologia de Ensino e do Programa de Pós-Graduação em Educação da UFSCar. E-mail: montroneufscar@gmail.com
} 


\section{INTRODUÇÃO}

Por meio das reflexões e ações com aqueles e aquelas que também acreditam não estarem no mundo (no sentido de a ele se adaptar), mas ao mundo, com respeito e vagar, transformarem-se e transformá-lo, compreendendo-se e reconhecendo-se, uns-com-osoutros-ao-mundo-que-está-sendo, em prol de uma sociedade menos desigual e mais solidária, consideramos o diálogo, o convívio, o estar com, e o educar-se em comunhão como processos intrínsecos à vida humana.

$\mathrm{Na}$ luta diária por tal modo de viver, em meio às práticas sociais em diferentes espaços/contextos vamos uns-com-os-outros-ao-mundo-que-está-sendo realizando trocas intersubjetivas de nossas experiências, de conhecimentos historicamente construídos de tal modo que, na medida de nossas partilhas culturais e sociais, construímos e constituímos nossa gentitude - ora incoerente, ora coerente, amorosa e humana - dentro e fora dos contextos acadêmicos.

Sem embargo, com base nos estudos de natureza qualitativa (MINAYO, 2013) e suleados por referenciais latino-americanos - tais como, Paulo Freire, Enrique Dussel, Ernani Maria Fiori e Petronilha Beatriz Gonçalves e Silva - este estudo se circunscreveu ao objetivo de descrever possibilidades de superação da negação do Outro e de seu reconhecimento em práticas sociais.

Para tanto, foi realizada uma incursão à literatura acerca das temáticas referentes à violência social, conceituação de Outro $^{3}$, práticas sociais e processos educativos, bem como algumas investigações já realizadas como possibilidades intencionalizadas e engajadas a um mundo mais justo, dialógico e, portanto, ético e humanizado.

Temos a expectativa que as reflexões desencadeadas neste e a partir deste estudo ampliem nossos horizontes, fomentando outras formas de perceber e caminhar uns-comos-outros-ao-mundo-que-está-sendo, particularmente no que tange às pesquisas em práticas sociais com grupos e comunidades populares.

\section{O OUTRO E A VIOLÊNCIA SOCIAL}

A partir da identificação das diversas formas de invasões culturais elitistas dos países nortistas e europeus, introjetadas às populações consideradas subdesenvolvidas em suma, provenientes do hemisfério Sul - é possível afirmar que os modos de viver de nossas sociedades latino-americanas, africanas e asiáticas vêm sendo, ao longo da história, subjugados, negados e violentados por uma lógica violenta e desumanizante, na qual somos cotidianamente impedidas e impedidos de ser.

Não obstante, torna-se essencial refletirmos sobre as perspectivas das buscas por melhoria de vida: trata-se de uma vida boa para quem? Para quem domina ou para quem é oprimido (DUSSEL, 2003)? De acordo com Dussel (1977a, p. 277), diante destas situações em que o diferente, o excluído, o Outro é considerado como não-ser, é necessário saber partir precisamente do centro da cultura popular para então construir e construir-se no processo de libertação, já que para "[...] criar algo novo é preciso ter uma palavra nova, que irrompe desde a exterioridade. Esta exterioridade é o próprio povo que parece estar totalmente no sistema e que na realidade é estranho a ele".

De acordo com Fanon (1983), o contexto opressor (chamado de colonial, pelo autor) se caracteriza pela dicotomia que inflige ao mundo: opressores e oprimidos,

\footnotetext{
${ }^{3}$ Conceito presente na obra de Enrique Dussel (tais como, DUSSEL, 1977a; 1977b; 1977c; 1994; 1995). Em síntese, com a letra “O” maiúscula (para diferenciar-se dos outros, com letra minúscula, enquanto outras pessoas em geral) representa os seres humanos socialmente discriminados, injustiçados, oprimidos e historicamente proibidos de ser.
} 
totalidade e exterioridade, centro e periferia. O processo de humanização, libertação, descolonialização, de deseurocentração, em contrapartida, unifica o mundo através de uma decisão radical de transformação social, que considera a unidade na diversidade das classes oprimidas.

Para Dussel (2002), a partir dos variados projetos invasivos e dominadores europeus sobre as culturas latinas, africanas e asiáticas, o Outro foi então rotulado como não-civilizado, como índio, inferior, bárbaro, não-ser, sendo assim, deixados à margem das decisões de suas próprias vidas, à exterioridade do sistema dominado pela elite opressora e desumanizante.

Com este viés, Dussel (1977b) formula conceitos justamente para romper com a tradição eurocêntrica do processo de pensar, refletir e compreender a nossa própria história, o que expressa um processo de descolonialização. Para Dussel (1977c, p. 4950):

[...] o Outro, o pobre, em sua extrema exterioridade do sistema, provoca à justiça; ou seja, chama (-voca) de frente (pro-). Para o sistema de injustiça "o outro é o inferno" (se por inferno se entende o fim do sistema, o caos agônico). Pelo contrário, para o justo o Outro é a ordem utópica sem contradições; é o começo do advento de um mundo novo, distinto, mais justo. A simples presença do oprimido como tal é o fim da boa consciência do opressor. Quem for capaz de descobrir onde se encontra o Outro, o pobre, poderá, a partir dele, fazer o diagnóstico da patologia do Estado.

Leal e Montrone (2013) indicam que a lógica opressora do pensamento colonizador, bem como o processo colonializador, pressupõem o Outro como inferior, como não-ser, pois, antes de colonizar, o "descobridor" já está com seu pré-projeto determinando: segregar, explorar, dominar, oprimir, conquistar e "civilizar". O Outro é a vítima: aquele ser humano que não criou o sistema opressor, mas dele faz parte; não é livre justamente por ser impedido de ser; historicamente, vêm sendo o índio, o negro, a mulher, a América Latina, a África, o hemisfério Sul, a natureza, a criança, o(a) jovem, o(a) velho(a), o(a) camponês(a), o(a) analfabeto(a).

Assim, ao contrário do que apregoavam os colonos em seu processo colonializador, a experiência de uns-com-os-outros-ao-mundo-que-está-sendo deve representar, a priori, o respeito àqueles e àquelas com quem trilhamos lado-a-lado nos caminhos processuais de nossas práticas sociais; representar o reconhecimento da experiência dos mais velhos e dos mais novos, de seus e nossos saberes de mundo-vida, bem como o solidário cuidado com quaisquer seres humanos, sejam crianças, adolescentes, jovens, adultos(as) ou idosos(as).

É possível afirmar que o Outro, na obra de Enrique Dussel, consiste nos denominados oprimidos na obra de Ernani Fiori e Paulo Freire. Segundo Andreola (1994, p. 12), "As múltiplas formas de miséria, fome, exploração e abandono dos povos famintos e condenados da terra, são tematizadas como 'exterioridade' e 'exclusão' por Dussel; como 'opressão' por Freire e Fiori', expressando o quanto as sociedades ao longo da história vêm violentando determinadas comunidades humanas negando-lhes às vezes desde a infância - a convivência dialógica, ética, amorosa, proibindo-as de ser.

Possuindo características contextuais, pluriconceituação e multifacetagens de efeitos históricos e culturais (MARTÍN-BARÓ, 1997), a violência social pode ser entendida como um processo inevitável à sociedade de classes, já que a materialização das diferentes relações econômicas com base na propriedade privada exige, para sua própria sustentação, a manifestação da violência social (SODRÉ, 2006), dentre outros modos desumanizantes - visíveis e invisíveis, mas sempre perceptíveis - de constituir- 
se, tais como a exploração da força de trabalho, lucro exacerbado, negligências ambientais e culturais/imateriais, por exemplo.

Eis a necessidade da conscientização e do processo contínuo da desocultação das verdades (FREIRE, 1987a) para que, a partir da reflexão crítica, na busca pela transcendência (SÉRGIO, 1999; SANTOS et al., 2007; GONÇALVES JUNIOR, 2010), aquilo que era invisível ontem passe a ser visível hoje às percepções humanas; aqueles que amavam menos ontem, amem mais hoje.

A afirmação do Outro como princípio de negação (DUSSEL, 1977c) é uma sorrateira forma ideológica de dominação. Tal premissa, ao longo dos processos de construção e desenvolvimento de nossas sociedades, faz parte de uma violenta e nãoamorosa lógica de viver das classes dominantes para o Outro (o não-civilizado, o diferente, o abandonado no caminho). Nesta lógica não me vejo no ou com o Outro e, assim, renego sua humanidade, o coisificando ao mesmo tempo em que nos desumanizo, isto é, só ajo de modo opressor, violento e não-amoroso contra alguém na medida em que me desumanizo.

\section{RECONHECENDO-SE COM O OUTRO}

Se a totalidade do Sistema de dominação, conforme Dussel (1994, p. 51), “[...] é feito por todos os que, tendo negado o outro termo da relação face-a-face, constituíram a si mesmos como os senhores do outro", a forma de superação deste sistema, que parte da exterioridade, inicia-se "[...] quando alguém reconstitui a relação com o outro como face-a-face" (DUSSEL, 1994, p. 51).

Conquanto, numa perspectiva dialética, "[...] para poder constituir a mera 'coisa' estendida no caminho como 'outro' era necessário antes 'ouvir a voz do outro' que clamava 'socorro!', 'tenho fome!' Mas, 'ouvir a voz do outro' é exatamente ter consciência ética" (DUSSEL, 1994, p. 51, grifos do autor), ou seja, nem mesmo "[...] a mais feroz dominação não é capaz de coisificar totalmente o homem" (FIORI, 1986, p. 6). Com estes pressupostos, é possível compreender que somos vocacionados à intersubjetividade, à alteridade, à abertura e proximidade ao Outro, para então, reconhecendo sua humanidade nos reconhecermos, unidos na diversidade $\mathrm{e}$ diversificados na unidade.

Contextualizando tais reflexões, dizer para uma pessoa não é o mesmo que dizer com uma pessoa. Realizando a troca do verbo e substituindo-o pelo verbo "escutar" torna-se possível contemplar melhor a diferença: quem escuta para alguém, está pressupondo a ausência da pessoa para quem se escuta; ao contrário, quando se escuta com alguém, a priori, estabelece-se uma relação de proximidade. É neste sentido que defendemos as relações de face a face, de comunhão, de reencontro com o Outro, de escrever/dizer/ouvir/fazer história junto, de intersubjetividade, de diálogo, de desocultação das verdades e das palavras verdadeiras ${ }^{4}$.

Tal qual a experiência que é considerada não como aquilo que se passa, aquilo que acontece, mas sim, como aquilo que nos passa, nos toca, nos acontece (LARROSABONDÍA, 2002), as diferentes faces da violência social só podem ser verdadeiramente

\footnotetext{
${ }^{4}$ Verdadeira no sentido freireano, o qual considera como palavra verdadeira aquela dita dialogicamente, eticamente, com anseios de desocultação das verdades. Segundo Freire (1987b, p. 44-45): “[...] se dizer a palavra verdadeira, que é trabalho, que é práxis, é transformar o mundo, dizer a palavra não é privilégio de alguns homens, mas direito de todos os homens. Precisamente por isto, ninguém pode dizer a palavra verdadeira sozinho, ou dizê-la para os outros, num ato de prescrição, com o qual rouba a palavra aos demais. O diálogo é este encontro dos homens, mediatizados pelo mundo, para pronunciá-lo, não se esgotando, portanto, na relação eu-tu".
} 
sentidas e negadas, de um lado, pelas pessoas que têm encarnada (MERLEAUPONTY, 1999) a dor da negação do ser, a fome nas entranhas, o frio dos olhares da totalidade do sistema, o abandono social vivido histórica e culturalmente; de outro lado, por aqueles e aquelas que, a partir da alteridade, do reconhecimento do Outro, na exterioridade, solidária, ética e amorosamente, irrompem a violência introjetada pela totalidade e, intencionam-se ao mundo na luta pela libertação, contra a coisificação e alienação dos seres humanos (DUSSEL, 1994).

Conforme Fiori (1991, p. 56), o mundo dos seres humanos "[...] é sempre uma constelação de valores, em cuja figura o homem vai traçando sua própria imagem". Isto significa afirmar que cada cultura, cada experiência humana ao mundo constitui processos de significação distintos e, ao reconhecer a humanidade do Outro, me reconheço enquanto gente e me constituo em meio às e a partir das relações intersubjetivas.

É neste sentido que podemos destacar o pensamento de Freire (1987b), no qual apreende-se que são os oprimidos quem libertam os opressores, pois estes, através de suas ações discriminadoras, opressoras, violentas, geram sua própria desumanização ao proibirem a plenitude do ser àqueles. Assim, é possível dizer:

[...] o estudo do pensamento (tradições e filosofia) na América Latina, Ásia
ou África não é uma tarefa episódica ou paralela ao estudo da filosofia pura e
simplesmente (que seria a européia); mas que se trata de uma história que,
como toda a razão, vem resgatando o contradiscurso não-hegemônico,
dominado, silenciado e esquecido, o da Alteridade que constitui a própria
modernidade (DUSSEL, 1995, p. 95, grifos do autor).

Não obstante, em quaisquer relações estabelecidas, numa perspectiva libertadora (FREIRE, 1987a; 1987b; 1992; 1995; 2000a; 2000b; 2001a; 2001b), nossos discursos e projetos de mundo devem buscar a coerência com nossas ações, estando ontologicamente a favor do ser humano. Segundo Freire (2000b, p. 55) "A luta ideológica, política, pedagógica e ética a lhe ser dada por quem se posiciona numa opção progressista não escolhe lugar nem hora".

De igual modo, tal como afirma Dussel (2002, p. 519), "A ética da libertação é uma ética possível acerca de toda ação de cada dia. No entanto, o próprio dessa ética, ou seu referente privilegiado, é a vítima ou comunidade de vítimas que operará com o/s 'sujeito/s' em última instância".

Como podemos, sendo latino-americanos e latino-americanas que vivem em uma região historicamente invadida e explorada pelo projeto europeu, colonizador e colonializador, seja nas esferas política, econômica, cultural ou territorial de nossos povos, ainda não estarmos educando-nos de modo a perceber e fazer algo contra as atrocidades a nossa gente? Como diria Fiori (1987, p. 37), "Nós estamos dentro de uma multidão de entes. Que é isso? Uma dispersão? Uma diáspora total? Um estar fechado completamente, em relação ao outro? Todos eles formam um universo, ou constituem um absurdo e impensável multiverso?".

No entanto, mesmo depois de tomada consciência da barbárie aos povos latinoamericanos, africanos, comunidades indígenas e tantos outros povos, como é possível, passadas tantas luas e sóis em nossa própria terra, ainda assim cometer "deslizes" em pensamentos e ações a ponto de renegar nossa própria cultura, nossos semelhantes e, por isto mesmo, renegar-nos?

Ressalvamos que as classes populares não são apenas um bloco dos oprimidos, de marginalizados e improdutivos, como bem advoga Dussel (1994): ao mesmo tempo em que é socialmente excluída, a classe popular radia sua existência e resistência contra- 
ideológica em meio às suas práticas sociais. Assim, é necessário deixar em "suspensão" nossos pré-conceitos, nossas certezas; concebendo o corpo encarnado (MERLEAUPONTY, 1999) e não como seres ou "objetos" abstratos, passando então a não apenas "dar voz" ao diferente (já que parte-se da premissa que todos e todas têm voz), mas sim, estar com ouvidos/braços/percepções abertas, estar-sendo junto, escrever história junto, considerando as diferenças como diferenças, e não como representações de superioridade e inferioridade.

De tal modo, "A consciência abre-se e nos atira fora, junto às coisas, mas abre-se também, para que, nela, as coisas entrem e se objetivem. Na abertura das consciências, somos e não somos a coisa que conhecemos; aí estamos fora da coisa e fora de nós" (FIORI, 1963, p. 18). Assim, torna-se coeso indicar algumas possibilidades de compreensão com o Outro, a partir da experiência do face a face, da identificação e reconhecimento de sua humanidade, de suas práticas sociais e de seus processos educativos, emaranhadas a perspectivas dialógicas de convivência, incluindo pesquisas acadêmicas no campo da educação - particularmente com as comunidades e grupos populares, por exemplo.

\section{PRÁtICAS SOCIAIS E PROCESSOS EDUCATIVOS: PERSPECTIVAS SULEADORAS}

Ao longo da história da Educação brasileira, segundo Severino (1995) e Marcellino (1995), foram estabelecidas duas grandes correntes filosóficas sob as quais observamos reflexos até os dias atuais: uma é derivada da tradição metafisica clássica, com grande influência da Igreja Católica; e outra relacionada à revolução epistemológica iluminista ocorrida em grande escala na Europa, disseminando suas concepções naturalistas e cientificistas à realidade brasileira através do positivismo.

A partir destes e diversos outros desdobramentos das invasões culturais (relacionados à dominação no período da colonização, por exemplo, e ao processo colonializador subsequente), a razão científica tornou-se referência básica ao existir humano em nossa sociedade e, assim, passamos a desvalorizar outras formas, espaços e possibilidades de saberes e manifestações humanas (GALEANO, 1979; MARCELLINO, 1983; 1995; ALVES, 1988; GONÇALVES JUNIOR, 2010).

De acordo com Gonçalves Junior (2010, p. 50), "No atual contexto de globalização, no entanto, ainda percebemos formas de colonização e folclorização de práticas e povos não europeus ou estadunidenses, principalmente via meios de comunicação de massa". Para além do contexto brasileiro - mas que também nos diz respeito, uma vez que somos seres humanos - tais aspectos são historicamente propagados e naturalizados, como nos casos dos países da América Latina e África.

De um modo geral, as práticas sociais, saberes e a própria cultura do contexto do hemisfério sul são desclassificadas e renegadas à exterioridade (DUSSEL, 1977c) pela lógica do eurocentrismo (QUIJANO, 2010; ARAÚJO-OLIVERA, 2014), havendo, assim, a separação entre cultura erudita e a cultura popular (BRANDÃO, 1984), de modo que esta, a oprimida, é considerada proveniente do sul, da periferia, e está na exterioridade (DUSSEL, 1977c); enquanto aquela, a dominante, é oriunda do norte, do centro e representa a totalidade do sistema-mundo (DUSSEL, 1977c).

Contudo, "[...] lutar contra uma dominação cada vez mais polifacetada significa perversamente lutar contra a indefinição entre quem domina e quem é dominado, e, muitas vezes, lutar contra nós próprios” (SANTOS; MENESES, 2010, p. 18).

Não é simples, então, realizar o movimento de desnaturalização e suleação do olhar/sentir/perceber os fenômenos e o próprio viver, considerando que "[...] é difícil enxergar com clareza as coisas que estão muito próximas de nós, sobretudo quando elas 
já se encontram ali desde que nascemos, fazendo parte da nossa rotina e compondo o cenário do nosso cotidiano" (ALVES, 1988, p. 07).

Por convivermos com esses fenômenos rotineiramente, acabamos concebendo e teorizando muitas coisas como sendo "[...] naturais, raramente questionando suas origens, razões de ser, funções reais, a quem estão beneficiando e como poderia ser nossa vida sem elas" (ALVES, 1988, p. 07).

Brandão (2005, p. 186) nos apresenta a seguinte concepção: “[...] criamos a cada dia o mundo onde vivemos, mesmo quando ele parece mover-se ou deixar-se por conta própria e fora de nosso alcance". Tal qual Martins (1992), podemos refletir: em que medida estamos realmente interessados e interessadas sobre o sentido do humano?

Em outras palavras, como o nosso teorizar tem encaminhado o nosso agir e viceversa? Isto porque, compreendemos que o teorizar implica reflexão, direcionamento e sistematização do pensamento, das palavras, dos dizeres, do que foi escutado e experienciado, bem como a meditação e crítica das informações, do que se projeta. $\mathrm{O}$ teorizar pode ser caracterizado como uma das formas de expressão do pensamento, um encaminhamento para o agir.

O teorizar - academicamente ou não - também não se constitui fora de uma realidade, de um contexto, de um certo tempo e espaço: ela se dá a partir das relações, da intersubjetividade, das experiências de uns-com-os-outros-ao-mundo-que-está-sendo. Couto (2002) e Diniz (2008), por exemplo, indicam que as relações intersubjetivas nos possibilitam a constituição de nossos saberes.

Com a perspectiva da valorização e do reconhecimento dos diferentes modos de se caminhar e compreender tal processo com os seus e as suas caminhantes, sob o ponto de vista dos grupos/comunidades que a realidade em que vivem os(as) excluem e os(as) desqualificam, incluindo seus próprios saberes, podemos citar Oliveira et al. (2009; 2014a; 2014b), Araújo-Olivera (2014), Oliveira e Sousa (2014) e Silva (2014), uma vez que se debruçam aos processos educativos em práticas sociais.

As práticas sociais são concebidas como espaços/contextos nos quais há relações sociais que possibilitam e desencadeiam a luta pela existência dessas comunidades/grupos, tendo em vista que no trajeto caminhado para a reprodução ou superação das desigualdades (oriundas, dentre outros, a partir do pensamento colonializador e eurocentrado), através dos processos educativos desenvolvidos ocorre a construção das identidades de cada uma das pessoas na sociedade (OLIVEIRA et al., 2009; 2014a; 2014b; ARAÚJO-OLIVERA, 2014; OLIVEIRA; SOUSA, 2014; SILVA, 2014).

Fundamentando-se em autores como Paulo Freire, Enrique Dussel e Ernani Maria Fiori, Silva (2004, p. 01) defende que as práticas sociais são estabelecidas nas e a partir das "[...] ações e relações que as pessoas e os grupos mantêm entre si para passar as normas de vida, de manutenção ou transformação da sociedade". Neste sentido, é possível sublinhar que as práticas sociais:

[...] decorrem de e geram interações entre indivíduos e entre eles e os ambientes natural, social e cultural em que vivem. Desenvolvem-se no interior de grupos, de instituições, com o propósito de produzir bens, transmitir valores, significados, ensinar a viver e a controlar o viver; enfim, manter a sobrevivência material e simbólica das sociedades humanas. As práticas sociais tanto podem enraizar como desenraizar ou levar a criar novas raízes (OLIVEIRA et al., 2014b, p. 33).

De forma complementar: 
As práticas sociais se estendem em espaço/tempo construídos por aqueles que delas participam, seja compulsoriamente, seja por escolha política ou de outra natureza. Sua duração - permanência, desaparecimento, transformação depende dos atores que as constroem, desenvolvem, mantêm ou suprimem, bem como dos objetivos que com elas se quer atingir e do momento histórico. [...] As práticas sociais nos encaminham para a criação de nossas identidades. [...] Nelas, as pessoas expõem, com espontaneidade ou restrições, modos de ser, pensar, agir, perceber experiências produzidas na vida, no estudo de problemas e dificuldades, com o propósito de entendê-los e resolvê-los (OLIVEIRA et al., 2014b, p. 34-35).

Neste sentido, através do convívio amistoso, tenso, acolhedor, excludente, contraditório - e portanto, dialético - as classes populares vão se educando em práticas sociais "[...] na sua humanidade para a cidadania negada, conquistada, assumida" (OLIVEIRA et al., 2014b, p. 35), já que "[...] é comum o olhar para a negatividade, no qual se supõe que pouco ou nada se aprende nas práticas sociais protagonizadas por essas pessoas" (OLIVEIRA et al., 2014a, p. 118). Assim, "As experiências de uns com os outros na interação com o mundo são condições necessárias para decifrarmos o mundo" (COTA, 2000, p. 211).

É possível destacar que os processos educativos não têm sua origem e seu desenvolvimento apenas no ambiente escolar (SILVA, 2004; OLIVEIRA et al., 2009; 2014a; 2014b), uma vez que todas as pessoas possuem conhecimentos sobre algo (FREIRE, 1989; 1992). Neste sentido, nas concepções em que há buscas por compreender o ser humano em sua totalidade, fornido das possibilidades de transcendência, ou seja, do ser mais (SÉRGIO, 1999; 2004; DUSSEL, 2002; SANTOS et al., 2007; GONÇALVES JUNIOR, 2010), na constituição desses saberes por meio das relações humanas estabelecidas em diferentes contextos, os processos educativos vão sendo construídos, significados e ressignificados.

Nas palavras de Brandão (1984), todo momento de construção de saberes, que é eminentemente coletivo, nas classes populares, já é um trabalho político e, portanto, libertador. Igualmente, “[...] é também um meio através do qual o sujeito que 'se educa' torna-se consciente do que é, do que faz e do que pode fazer, das condições em que vive e do que deve realizar para transformá-las" (BRANDÃO, 1984, p. 29).

Para Fiori (1991), os processos educativos se constituem com o pressuposto da libertação, isto é, tendo a perspectiva da educação enquanto prática libertadora e "[...] a educação é o esforço permanente do homem por constituir-se e reconstituir-se, buscando a forma histórica na qual possa re-encontrar-se consigo, mesmo, em plenitude de vida humana, que é, substancialmente, comunhão social" (FIORI, 1991, p. 83). Assim, ao mesmo tempo em que os seres humanos exercem a dominação do mundo, também praticam e possibilitam diferentes caminhos de humanização e processos de libertação.

Isto nos indica que, ao construirmos os nossos processos educativos em meio às e a partir das práticas sociais das quais as constituímos e fazemos parte, estamos educando-nos, conhecendo a nós e aos demais seres humanos tensionados pela direcionalidade/projetividade de nossa consciência, de nossas intersubjetividades na/à construção de nossos processos educativos e, igualmente, à transcendência do ser.

\footnotetext{
Neste sentido, ao invés de nos perguntarmos "se" as práticas sociais e os processos educativos, constituídos e desenvolvidos no interior de grupos e comunidades populares, estão ocorrendo ou não nessa direção, preferimos buscar compreender "quando?", “onde?" e "como?" estão acontecendo (LEAL; OLIVEIRA, 2011, p. 5).
} 
No âmbito das pesquisas com este prisma, se faz necessário um paciente e respeitoso processo de aproximação e, em continuidade, a inserção em si, na e por meio da convivência dialógica investigativa. A postura de distanciar-se também se faz necessária, pois “[...] nos possibilita estranhar [o que não significa/justifica o preconceito], inclusive e especialmente, o que é familiar. A visão corre em parte através dos olhos, mas não inteiramente. Há um olhar interior que enxerga o invisível" (OLIVEIRA et al., 2014b, p. 42). Portanto, abrindo-se ao diferente, ao novo, com um estranhamento respeitoso buscar-se-á o desvelamento e a compreensão das diferentes formas de como as pessoas educam-se ao longo do viver em meio as práticas sociais.

\section{PROCESSOS EDUCATIVOS EM PRÁTICAS SOCIAIS: ALGUMAS POSSIBILIDADES}

Com uma perspectiva libertadora e não sectária; social e historicamente condicionada, mas não determinada; progressista e não fatalista, as pesquisas em práticas sociais não devem deixar de se aproximar e se familiarizar "[...] com a sintaxe, com a semântica dos grupos populares, de entender como fazem eles sua leitura do mundo, de perceber suas 'manhas' indispensáveis à cultura de resistência que se vai constituindo e sem a qual não podem defender-se da violência a que estão submetidos" (FREIRE, 1992, p. 107).

Aquele ou aquela que se insere em comunidades com o intento de realizar pesquisa de maneira ética, deve lembrar que "O seu quefazer, ação e reflexão, não pode dar-se sem a ação e a reflexão dos outros, se seu compromisso é o da libertação" (FREIRE, 1987b, p. 143). São necessárias, para tanto, a inserção paciente, o pensar autêntico, a palavra verdadeira, o convívio dialógico, a problematização da situação com cada sujeito no processo (de reproduzir, pesquisar, aprender, lutar, conhecer ou conviver, por exemplo), de modo a respeitar a diversidade, bem como o reconhecimento da unidade nesta.

Neste sentido, nos estudos com grupos e comunidades populares é essencial que nossas ações estejam integradas e comprometidas com seus membros, nos sensibilizando com e procurando, atenta e colaborativamente (LEAL, 2009; LEAL; ZANINI; RODRIGUES, 2010), compreender suas palavras, valores, ações, significações da realidade e o próprio silêncio (LEAL, 2009), ao mesmo tempo em que, coletivamente, buscamos superar a discriminação e a naturalização das desumanidades sobre os fenômenos construídos/vividos, social e historicamente, em nossas realidades.

Compreendendo "[...] o ser de modo integral existindo-aí-no-mundo-com-osoutros, em condição de abertura para a experiência [...], nessa abertura, não há possibilidade de fragmentação" (GONÇALVES JUNIOR, 2010, p. 52, grifos do autor), nem do ser e tampouco de seus saberes, seu contexto de mundo-vida, sua cultura e suas experiências em práticas sociais, pois, desde que nascemos nos encontramos impregnados e impregnadas de cultura (SILVA, 1987).

Considerando que as pessoas não vivem uma mesma experiência da mesma maneira (VALLA, 1996; MERLEAU-PONTY, 1999; LARROSA-BONDÍA, 2002), Leal e Montrone (2018) afirmam que para a compreensão dos processos educativos é cogente um processo de inserção em que não apenas se respeite e se observe passivamente os fenômenos, mas sim, que se conviva no processo de construção dos saberes, das suas histórias e rede de significações dentro das práticas sociais. Um exemplo da riqueza desse viver com as comunidades participantes de um estudo é expresso por Oliveira (2003, p. 16-17): 
[...] estava mergulhada num processo vivo de educação, o qual me dispunha a compreender. Local privilegiado. Em movimentos, ora suaves ora abruptos, ora lentos ora vertiginosos, ora leves ora sufocantes, ora harmoniosos ora ensurdecedores, vidas, vivências, amizades, sabores, cheiros, texturas, sons, palavras, cores, lágrimas e sorrisos teciam uma rede que me embalava e em cada movimento seu me punha também em movimento, me direcionava o olhar, mostrava- me, em novas perspectivas, o que se punha a ver. Assim, pude ad-mirar o mundo no qual imergia, com vagar, de modo a se constituir verdadeiramente em experiência.

Oliveira et al. (2014a) afirmam que o convívio dentro das práticas sociais possibilita o entendimento da experiência do Outro, mas para tanto, a inserção dos pesquisadores ou das pesquisadoras na comunidade deve contemplar um estranhamento respeitoso à cultura do Outro, de modo a reconhecer suas falas, sua leitura e visão de mundo, mas sem abdicar as raízes de quem pesquisa ou participa de tal prática social.

Os processos educativos em práticas sociais não são manifestados especificamente em um dado momento: por se tratar de um processo, exige convivência, lealdade, abertura ao diferente, reciprocidade, confiança, respeito, amizade, simpatia e empatia. Constituem-se como uma dinâmica complexa, dialética (pois, para conhecer ao Outro, preciso conhecer a mim e vice-versa), e exige um contínuo caminhar (e às vezes descansar) junto, face a face, em direção à compreensão das diferentes formas em que as pessoas se educam umas-com-as-outras, intersubjetivamente.

"Dizendo de outro modo, chamam nossa atenção processos educativos em que as pessoas vão construindo jeitos de ser, viver, conviver umas com as outras, nos ambientes que herdaram e onde atuam, convivem e também naqueles que criam" (SILVA, 2014, p. 19). Para Leal e Montrone (2018), investigar processos educativos, nesta perspectiva, não se traduz na procura exclusiva pelo "produto", em termos estritamente quantitativos, em termos da pressa ou da lógica da produtividade no educar-se humano: os processos educativos podem ser compreendidos como o conjunto de saberes expressados, ocultados, interiorizados e/ou simbolizados no como nos educamos com as outras pessoas ao longo de nossa existência, histórica e culturalmente, em diferentes práticas sociais.

Oliveira et al. (2009) descrevem alguns estudos com pessoas e grupos/comunidades latino-americanos marginalizados pela sociedade, com os objetivos voltados à compreensão de processos educativos em práticas sociais. Há menções como: o educar-se dos negros trabalhadores rurais do Limoeiro-RS (SILVA, 1987); prática social lazer entre trabalhadores em empresas transnacionais (LEMOS, 2007); ou entre crianças (GONÇALVES JUNIOR; SANTOS, 2006), dentre outros estudos.

Com Barbosa (2008), há a construção de uma cartilha educativa sobre direitos sexuais e reprodutivos com jovens, indicando que estes(as) possuem muitos saberes do seu corpo, sua saúde, sua sexualidade, além da curiosidade e partilha de conhecimentos. Podemos citar, ainda, Joly e Montrone (2008), onde as autoras sublinham aprendizagens musicais e sociais representadas pelo respeito às diferenças, pela paciência com os demais, pela amizade e solidariedade entre as pessoas de diferentes idades em uma orquestra comunitária.

O pedir nos semáforos através da oralidade e através do malabarismo foram práticas sociais descritas por Leal e Montrone (2018), nas quais o respeito e o reconhecimento pela própria humanidade foram processos educativos identificados pelo pesquisador e pela pesquisadora a partir da investigação empreendida com malabaristas e moradores de rua em meio a veículos, calçadas e semáforos de cruzamentos viários. 
Em todos os estudos mencionados foram obtidas significativas contribuições no desvelar/compreender/experienciar processos educativos, tanto pelas pessoas colaboradoras ao longo de suas práticas sociais, quanto aos/às pesquisadores(as), no e a partir do convívio dialógico investigativo estabelecido, considerando-se a diversidade de experiências e culturas imbricadas nas relações de uns-com-os-outros-ao-mundo-queestá-sendo.

\section{ALGUMAS CONSIDERAÇÕES}

Gonçalves Junior (2010, p. 53) cita que a esfera de ações e relações nos diferentes grupos e comunidades não pode simplesmente ser circunscrita e limitada a objeto de nosso ensino/pesquisa, "[...] tampouco as situações em que tais pessoas se encontram e em que vivem, lutam, transformam e produzem conhecimento como situações imutáveis ou definitivas, pois o próprio ser é inacabado e condenado ao estar sendo, ao vir-a-ser".

Por isso, os processos de pesquisa em práticas sociais, com grupos e comunidades populares, numa perspectiva ética, crítica - e, portanto, rigorosa e transformadora - não podem se estabelecer de maneira hierárquica e preconceituosa, coisificando seus próprios integrantes e, então, compactuando com os diferentes processos de violência social: o diálogo, o estranhamento respeitoso, a convivência e o agir com são inerentes à concretização de investigações em práticas sociais, de modo a compreender seus diferentes processos educativos.

Neste viés, não é coerente simplesmente coletar dados de "objetos de estudo" que escolhemos investigar - como quem, numa prateleira, escolhe os itens que levará para o trabalho: exatamente por exigir rigorosidade metodológica e ética científica, pesquisadoras e pesquisadores em práticas sociais e em quaisquer estudos com seres humanos devem ser compromissados(as) com aqueles e aquelas que decidem colaborar com as pesquisas.

De tal forma, caminharemos em vivos e diversificados processos de compreensão e reconhecimento do Outro, de superação da violência social, de humanização e libertação. "Para tanto, é preciso que tenhamos em mente que não sou eu que estou no mundo em busca de tal libertação, mas sim, um eu constituído por um nós, um nós sendo uns com os outros, interagindo e dialogando com/ao/no mundo" (LEAL, 2009, p. $563)$.

Estranhar e estranhar-se, respeitar, confiar, empatizar, dialogar, caminhar no face a face são ações de amorosidade imperativas ao reconhecimento da humanidade do Outro e, portanto, dos nossos próprios processos de superação das multifaces da violência social. À vista disto, torna-se possível a construção de laços, afetos e costuras mutuamente solidárias, na abertura para o desvelar e o tecer dos processos educativos e de humanização ao longo do convívio dialógico, investigativo ou não, em práticas sociais.

\section{REFERÊNCIAS}

ALVES, J. F. A invasão cultural norte-americana. São Paulo: Moderna, 1988.

ANDREOLA, B. A. Prefácio. In: DAMKE, I. R. O processo do conhecimento na pedagogia da libertação: as idéias de Freire, Fiori e Dussel. Petrópolis: Vozes, 1994, p. 11-15.

ARAÚJO-OLIVERA, S. S. Exterioridade: o outro como critério. In: OLIVEIRA, M. W.; SOUSA, F. R. (Orgs.). Processos educativos em práticas sociais: pesquisas em educação. São Carlos: EDUFSCar, 2014. p. 47-112. 
Paulo Henrique Leal; Aida Victoria Garcia Montrone

BARBOSA, D. C. Processos educativos entre jovens na construção de uma cartilha educativa sobre direitos sexuais e reprodutivos. 162 f. Dissertação (Mestrado em Educação) - Universidade Federal de São Carlos, São Carlos, 2008.

BRANDÃO, C. R. A canção das sete cores: educando para a paz. São Paulo: Contexto, 2005.

BRANDÃO, C. R. Saber e ensinar: três estudos de educação popular. Campinas: Papirus, 1984.

COTA, M. C. De professores e carpinteiros: encontros e desencontros entre teoria e prática na construção da prática profissional. Educação e Filosofia, v. 14, n. 27-28, p. 203-222, 2000.

COUTO, M. Cada homem é uma raça: estórias. 8. ed. Lisboa: Caminho, 2002.

DINIZ, E. R. Um rio chamado tempo, uma casa chamada terra, de Mia Couto: identidades em trânsito. 123 f. Dissertação (Mestrado em Estudos Literários) - Universidade Federal de Minas Gerais, Belo Horizonte, 2008.

DUSSEL, E. Alguns princípios para uma ética ecológica material de libertação (relações entre a vida na terra e a humanidade). In: PIXLEY, J. (Coord.). Por um mundo diferente: alternativas para o mercado global. Petrópolis: Vozes, 2003. p. 23-35.

DUSSEL, E. Ética da libertação na idade da globalização e da exclusão. 2. ed. Petrópolis: Vozes, 2002.

DUSSEL, E. Ética da libertação: crítica à ideologia da exclusão. São Paulo: Paulus, 1995.

DUSSEL, E. Ética comunitária. 3. ed. Petrópolis: Vozes, 1994.

DUSSEL, E. Cultura imperial, cultura ilustrada e libertação da cultura popular. In: DUSSEL, E. Para uma ética da libertação latino americana III: erótica e pedagógica. São Paulo: Loyola; Piracicaba: UNIMEP, 1977a. p. 253-281.

DUSSEL, E. A pedagógica latino-americana (a Antropológica II). In: DUSSEL, E. Para uma ética da libertação latino americana III: erótica e pedagógica. São Paulo: Loyola; Piracicaba: UNIMEP, 1977 b. p. 153-251.

DUSSEL, E. Filosofia da libertação - filosofia na América Latina. São Paulo: Loyola; UNIMEP, 1977c.

FANON, F. Los condenados de la tierra. 7. ed. México: Fondo de Cultura Económica, 1983.

FIORI, E. M. Textos escolhidos: educação e política. Porto Alegre: L\&PM, 1991.

FIORI, E. M. Textos escolhidos: metafísica e história. Porto Alegre: L\&PM, 1987.

FIORI, E. M. Conscientização e educação. Educação e Realidade, v. 11, n. 01, p. 3-10, jan./jun. 1986.

FIORI, E. M. Abstração metafísica e experiência transcendental. Porto Alegre: Gráfica Moderna, 1963.

FREIRE, P. Algumas reflexões em torno da utopia. In: FREIRE, Ana Maria Araújo. Pedagogia dos sonhos possíveis. São Paulo: UNESP, 2001a. p. 85-86.

FREIRE, P. Política e educação: ensaios. 5. ed. São Paulo: Cortez, 2001 b.

FREIRE, P. Educação na cidade. 4. ed. São Paulo: Cortez, 2000a.

FREIRE, P. Pedagogia da indignação: cartas pedagógicas e outros escritos. São Paulo: Editora UNESP, 2000b.

FREIRE, P. À sombra desta mangueira. 2. ed. São Paulo: Olho d’Água, 1995. 
FREIRE, P. Pedagogia da esperança: um reencontro com a pedagogia do oprimido. 3. ed. Rio de Janeiro: Paz e Terra, 1992.

FREIRE, P. A importância do ato de ler: em três artigos que se completam. São Paulo: Autores Associados/Cortez, 1989.

FREIRE, P. Educação como prática da liberdade. 18. ed. Rio de Janeiro: Paz e Terra, 1987a.

FREIRE, P. Pedagogia do oprimido. 17. ed. Rio de Janeiro: Paz e Terra, 1987b.

GALEANO, E. As veias abertas da América Latina. 8. ed. Rio de Janeiro: Paz e Terra, 1979.

GONÇALVES JUNIOR, L. Etnomotricidade: multiculturalismo e educação física escolar. In: CARREIRA FILHO, D.; CORREIA, W. R. (Orgs.). Educação física escolar: docência e cotidiano. Curitiba: Editora CRV, 2010. p. 49-67.

GONÇALVES JUNIOR, L.; SANTOS, M. O. Brincando no jardim: processos educativos de uma prática social de lazer. In: CONGRESSO NACIONAL DE EDUCAÇÃO, 6., 2006. Anais... Curitiba, v. 1, 2006. p. 1-14.

JOLY, M. C. L.; MONTRONE, A. V. G. Convivência em uma orquestra comunitária: um olhar para os processos educativos. In: ENCONTRO NACIONAL DA ABEM - DIVERSIDADE MUSICAL E COMPROMISSO SOCIAL: O PAPEL DA EDUCAÇÃO MUSICAL, 17., 2008. Anais... São Paulo, 2008. p. $1-5$.

LARROSA-BONDÍA, J. Notas sobre a experiência e o saber de experiência. Revista Brasileira de Educação, n. 19, p. 20-28, 2002.

LEAL, P. H. Práticas sociais e processos educativos em um abrigo de idosos e idosas: o convívio no jogo de dominó. In: COLÓQUIO DE PESQUISA QUALITATIVA EM MOTRICIDADE HUMANA: AS LUTAS NO CONTEXTO DA MOTRICIDADE / SIMPÓSIO SOBRE O ENSINO DE GRADUAÇÃO EM EDUCAÇÃO FÍSICA: 15 ANOS DO CURSO DE EDUCAÇÃO FÍSICA DA UFSCAR / SHOTOWORKSHOP, 4. / 3. / 5., 2009, São Carlos. Anais... São Carlos: SPQMH/UFSCar, 2009. p. 561606.

LEAL, P. H.; MONTRONE, A. V. G. Do olhar nos faróis ao convívio com malabaristas: a prática social do pedir nos semáforos. Revista Educação e Cultura Contemporânea, v. 15, n. 38, p. 265-294, 2018.

LEAL, P. H.; MONTRONE, A. V. G. O escutar e o dizer no aprender a viver: ensaio sobre a oralidade e a cultura africana a partir do documentário pátria proibida. In: SEMINÁRIO DE PRÁTICAS SOCIAIS E PROCESSOS EDUCATIVOS: CONTRIBUIÇÕES DE PETRONILHA BEATRIZ GONÇALVES E SILVA, 4., 2013, São Carlos. Anais... São Carlos: UFSCar, 2013. p. 1-10.

LEAL, P. H.; OLIVEIRA, M. W. Apresentação. In: SEMINÁRIO DE PESQUISAS EM PRÁTICAS SOCIAIS E PROCESSOS EDUCATIVOS: 90 ANOS DO NASCIMENTO DE PAULO FREIRE, 3., 2011, São Carlos. Anais... São Carlos: UFSCar, 2011. p. 05-06.

LEAL, P. H.; ZANINI, G. S.; RODRIGUES, S. T. A colaboração no Aikido: refletindo sobre processos de conscientização e humanização. In: CONGRESSO NACIONAL DE EDUCAÇÃO FÍSICA / REUNIÃO CIENTÍFICA - EDUCAÇÃO FÍSICA, 4. / 15., 2010, Bauru. Anais... Bauru: UNESP, 2010. p. 47-48.

LEMOS, F. R. M. Compreensões de trabalhadores em transnacionais de São Carlos acerca da prática social lazer: processos educativos envolvidos. 198 f. Dissertação (Mestrado em Educação) Universidade Federal de São Carlos, São Carlos, 2007.

MARCELLINO, N. C. Lazer e educação. 3. ed. Campinas: Papirus, 1995.

MARCELLINO, N. C. Lazer e humanização. Campinas: Papirus, 1983. 
MARTÍN-BARÓ, I. Violencia y agresión social. In: MARTÍN-BARÓ, I. Acción e ideología: psicología social desde Centroamérica. 8. ed. El salvador: UCA, 1997. p. 359-422.

MARTINS, J. Um enfoque fenomenológico do currículo: educação como poíesis. São Paulo: Cortez, 1992.

MERLEAU-PONTY, M. Fenomenologia da percepção. São Paulo: Martins Fontes, 1999.

MINAYO, M. C. Souza. (Org.). Pesquisa social: teoria, método e criatividade. 33. ed. Petrópolis: Vozes, 2013.

OLIVEIRA, M. W. Processos educativos em trabalhos desenvolvidos entre comunidades: perspectivas de diálogo entre saberes e sujeitos. $141 \mathrm{f}$. Trabalho de Pesquisa (Pós-Doutorado) - Fundação Oswaldo Cruz, Rio de Janeiro, 2003.

OLIVEIRA, M. W.; RIBEIRO JUNIOR, D.; SILVA, D. V. C.; SOUSA, F. R.; VASCONCELOS, V. O. Pesquisando processos educativos em práticas sociais: reflexões e proposições teórico-metodológicas. In: OLIVEIRA, M. W.; SOUSA, F. R. (Orgs.). Processos educativos em práticas sociais: pesquisas em educação. São Carlos: EDUFSCar, 2014a, p. 113-141.

OLIVEIRA, M. W.; SILVA, P. B. G.; GONÇALVES JUNIOR, L.; GARCIA MONTRONE, A. V.; JOLY, I. Z. Processos educativos em práticas sociais: reflexões teóricas e metodológicas sobre pesquisas em espaços sociais. In: REUNIÃO ANUAL DA ASSOCIAÇÃO DE PÓS-GRADUAÇÃO E PESQUISA EM EDUCAÇÃO, 32., 2009, Caxambu. Anais... Caxambu: ANPEd, 2009. p. 01-17.

OLIVEIRA, M. W.; SILVA, P. B. G.; GONÇALVES JUNIOR, L.; MONTRONE, A. V. G.; JOLY, I. Z. L. Processos educativos em práticas sociais: reflexões teóricas e metodológicas sobre pesquisa educacional em espaços sociais. In: OLIVEIRA, M. W.; SOUSA, F. R. (Orgs.). Processos educativos em práticas sociais: pesquisas em educação. São Carlos: EDUFSCar, 2014b. p. 29-46.

OLIVEIRA, M. W.; SOUSA, F. R. Apresentação. In: OLIVEIRA, M. W.; SOUSA, F. R. (Orgs.). Processos educativos em práticas sociais: pesquisas em educação. São Carlos: EDUFSCar, 2014. p. 710 .

QUIJANO, A. Colonialidade do poder e classificação social. In: SANTOS, B. S.; MENESES, M. P. (Orgs.). Epistemologias do sul. São Paulo: Cortez, 2010. p. 85-130.

SANTOS, B. S.; MENESES, M. P. Introdução. In: SANTOS, B. S.; MENESES, M. P. (Orgs.). Epistemologias do sul. São Paulo: Cortez, 2010. p. 15-27.

SANTOS, M. O.; GONÇALVES JUNIOR, L.; MARANHÃO, F.; LAGE, V.; MAIA, M. A. Estação comunitária do Jardim Gonzaga: processos educativos vivenciados na prática social do lazer. In: CONGRESSO NACIONAL DE EDUCAÇÃO: SABERES DOCENTES - EDIÇÃO INTERNACIONAL, 7., 2007, Curitiba. Anais... Curitiba: PUCPR, 2007. p. 1543-1555.

SÉRGIO, M. O desporto e a motricidade humana: teoria e prática. Povos e Culturas, Lisboa, n. 9, p. 4166, 2004.

SÉRGIO, M. A racionalidade epistémica na educação física do século XX. In: SÉRGIO, M. (Org.). O sentido e a acção. Lisboa: Instituto Piaget, 1999. p. 11-30.

SEVERINO, A. J. Prefácio. In: MARCELlinO, N. C. Lazer e educação. Campinas: Papirus, 1995. p. 09-12.

SILVA, P. B. G. Práticas sociais e processos educativos: da vida e do estudo até o grupo de pesquisa. In: OLIVEIRA, M. W.; SOUSA, F. R. (Orgs.). Processos educativos em práticas sociais: pesquisas em educação. São Carlos: EDUFSCar, 2014. p. 19-27. 
SILVA, P. B. G. O grupo de pesquisa "práticas sociais e processos educativos". In: SEMINÁRIO DE ESTUDOS DO GRUPO DE PESQUISA PRÁTICAS SOCIAIS E PROCESSOS EDUCATIVOS, 1., 2004, São Carlos. Anais... São Carlos: PPGE/UFSCar, 2004. p. 01-04.

SILVA, P. B. G. Educação e identidade dos negros trabalhadores rurais do limoeiro. 293 p. Tese (Doutorado em Educação) - Universidade Federal do Rio Grande do Sul, Porto Alegre, 1987.

SODRÉ, M. Sociedade, mídia e violência. 2. ed. Porto Alegre: Sulina/EDIPUCRS, 2006.

VALLA, V. V. A crise de interpretação é nossa: procurando compreender a fala das classes subalternas. Educação e Realidade, v. 21, n. 02, p. 177-190, jul./dez. 1996.

Recebido em: 21 mar. 2018.

Aprovado em: 23 abr. 2018. 